\title{
Pharmacology, Part 4: Nuclear Cardiology
}

\author{
Geoffrey M. Currie \\ Faculty of Science, Charles Sturt University, Wagga Wagga, Australia, and Regis University, Boston, Massachusetts
}

CE credit: For CE credit, you can access the test for this article, as well as additional JNMT CE tests, online at https://www.snmmilearningcenter.org. Complete the test online no later than June 2022. Your online test will be scored immediately. You may make 3 attempts to pass the test and must answer $80 \%$ of the questions correctly to receive $1.0 \mathrm{CEH}$ (Continuing Education Hour) credit. SNMMI members will have their CEH credit added to their VOICE transcript automatically; nonmembers will be able to print out a CE certificate upon successfully completing the test. The online test is free to SNMMI members; nonmembers must pay $\$ 15.00$ by credit card when logging onto the website to take the test.

Pharmacology principles provide key understanding that underpins the clinical and research roles of nuclear medicine practitioners in nuclear cardiology. The scope of practice of the nuclear medicine technologist demands knowledge and understanding of indications, contraindications, warnings, precautions, proper use, drug interactions, and adverse reactions for each medication to be used. This article is the fifth in a series of articles that aims to enhance the understanding of pharmacologic principles relevant to nuclear medicine. This article will build on the introductory concepts, terminology, and principles of pharmacology explored in the first 2 articles in the series. Specifically, this article will focus on the pharmacologic principles and complex relationship associated with interventional, adjunctive, and cessation medications in nuclear cardiology. Future articles will address the pharmacology related to the emergency crash cart and contrast medium associated with CT and MRI.

Key Words: adenosine; dipyridamole; dobutamine; nuclear cardiology; pharmacology

J Nucl Med Technol 2019; 47:97-110

DOI: 10.2967/jnmt.118.219675

$\mathbf{T}$ he scope of practice ( 1 ) for a nuclear medicine technologist defines interventional (imaging) medications as those medications used to evoke a specific physiologic or biochemical response used in conjunction with diagnostic imaging or therapeutic procedures (e.g., adenosine and dipyridamole). The same document ( 1 ) defines adjunctive medications as those medications used to respond to a patient's condition during a nuclear medicine procedure (e.g., salbutamol and aminophylline). Patients presenting to nuclear cardiology may be taking medication that can interfere with the nuclear medicine procedure and, in particular, the stress test component of the procedure. These represent

\footnotetext{
Received Aug. 27, 2018; revision accepted Nov. 13, 2018.

For correspondence or reprints contact: Geoffrey Currie, Faculty of Science, Locked Bag 588, Charles Sturt University, Wagga Wagga 2678, Australia

E-mail: gcurrie@csu.edu.au

Published online Feb. 15, 2019.

COPYRIGHT (C) 2019 by the Society of Nuclear Medicine and Molecular Imaging.
}

cessation medications, and the period of cessation is largely dependent on the half-life of the medication.

The scope of practice (1) for a nuclear medicine technologists requires that they display a thorough understanding and knowledge of indications, contraindications, warnings, precautions, proper use, drug interactions, and adverse reactions for each medication to be used. That knowledge development needs a foundation understanding of the principles of pharmacology provided in earlier articles in this series $(2,3)$. Indeed, these previous articles should be considered assumed knowledge for this article and the next in the series. To that end, those foundation principles will not be redefined here.

\section{PHARMACOLOGIC STRESS TESTING}

Stress myocardial perfusion imaging aims to create a disparity in blood flow between normal and stenosed arteries $(4,5)$. This can be achieved by either increasing the myocardial oxygen demand or vasodilating coronary arteries (Fig. 1) (6). Exercise is generally considered the preferred method of stress testing, but pharmacologic stress testing can overcome several limitations to exercise (5-8). There are essentially 2 approaches to pharmacologic stress testing: vasodilators and positive inotropic agents $(7,8)$. Vasodilators such as adenosine and dipyridamole have a direct and potent impact on coronary flow reserve to accentuate the blood flow differences between normal and diseased vessels by factors in the order of 3-4 (Fig. 2) $(5,7,8)$. Positive inotropic agents such as dobutamine increase cardiac workload, potentially inducing myocardial ischemia (Fig. 3) (5,7,8). Vasodilatory and positive inotropic-based interventional agents are discussed below and summarized in Table 1.

\section{Adenosine (Adenoscan or Adenocard [Astellas])}

General Information/Drug Class. Adenosine is a potent vasodilator endogenous adenine purine nucleoside that is a class $\mathrm{V}$ antidysrhythmic drug because of its effect on the atrioventricular node $(9,10)$.

Mode of Action. Adenosine is a natural regulator of blood flow and coronary demand, acting directly on adenosine cell surface receptors (Fig. 2) (9-12). Adenosine also modulates sympathetic neurotransmission $(11,12)$. There are 4 main adenosine receptor subtypes (9-11,13): $\mathrm{A}_{1}, \mathrm{~A}_{2 \mathrm{~A}}, \mathrm{~A}_{2 \mathrm{~B}}$, 


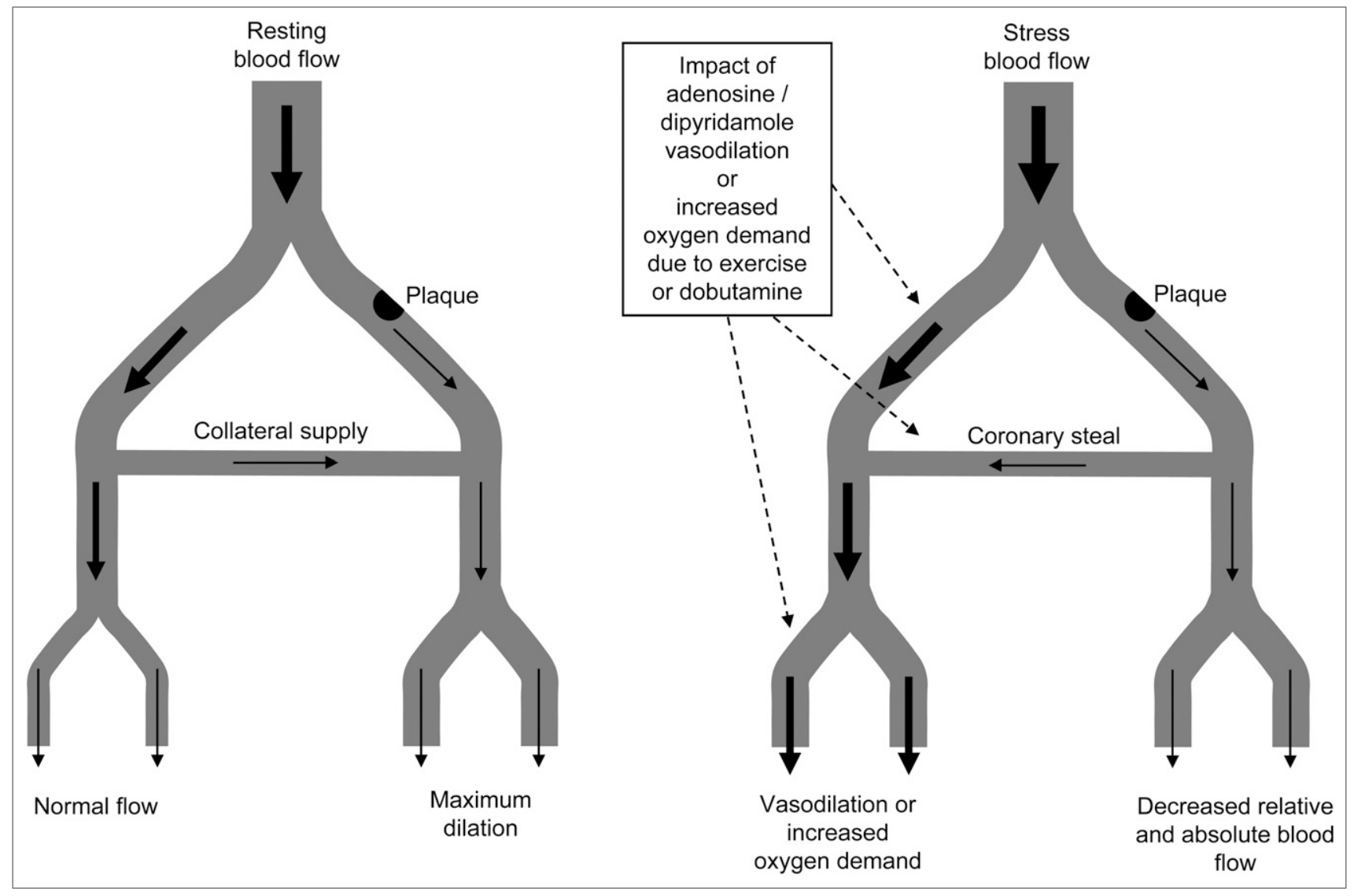

FIGURE 1. Schematic representation of general principle of pharmacologic stress in myocardial perfusion imaging. Ischemic myocardium may maintain resting blood supply with collateral vessels and resting vasodilation. Under pharmacologic vasodilation or increased oxygen demand (exercise or inotropic), blood flow difference between normal and stenosed vessels will exaggerate blood flow difference and expose coronary flow reserve (difference between maximum and resting flow rates). This may be further influenced by coronary steal.

and $\mathrm{A}_{3} . \mathrm{A}_{1}$ blocks atrioventricular conduction, reduces the force of cardiac contraction (negative inotropic and chronotropic action), and decreases glomerular filtration rate, cardiac depression, renal vasoconstriction, central nervous system (CNS) activity, and bronchoconstriction. $\mathrm{A}_{2 \mathrm{~A}}$ stimulates antiinflammatory response, vasodilation, decreased blood pressure, decreased CNS activity, inhibition of platelet aggregation, and bronchodilation. $\mathrm{A}_{2 \mathrm{~B}}$ stimulates phospholipase activity, release of mast cell mediators, and actions on the colon and bladder (contributes to bronchoconstriction). $\mathrm{A}_{3}$ stimulates phospholipase activity and release of mast cell mediators (contributes to bronchoconstriction).

Endogenous adenosine is produced in vascular smooth muscle cells and leaves the cell. In the extracellular space, endogenous and exogenous adenosine can couple with the 4 types of adenosine receptors outlined above. Receptors $A_{1}$ and $\mathrm{A}_{3}$ couple with an adenylate cyclase inhibitory $\mathrm{G}$ protein $(9,11)$. Receptors $A_{2 \mathrm{a}}$ and $\mathrm{A}_{2 \mathrm{~b}}$ couple with an adenylate cyclase-stimulating $\mathrm{G}$ protein $(9-11)$. Receptor $\mathrm{A}_{2 \mathrm{a}}$ specifically produces coronary and peripheral vasodilation by reducing intracellular calcium. Receptor $\mathrm{A}_{2 \mathrm{~A}}$ stimulates adenylate cyclase activity, which enhances the production of cyclic adenosine monophosphate to produce vasodilation and arterial smooth muscle relaxation $(9,10,14)$. As a result, normal arteries dilate whereas atherosclerotic arteries do not $(9,10)$. The resulting exaggeration in the difference between the blood flow in normal coronary arteries and the blood flow in atherosclerotic coronary arteries causes differential perfusion patterns.

Pharmacokinetics. Adenosine is rapidly transported inside the cell (erythrocytes and vascular endothelial cells), where it is rapidly metabolized to inosine via adenosine deaminase or to adenosine monophosphate via adenosine kinase-mediated phosphorylation $(14,15)$. This rapid transport and metabolism result in the very short half-life of less than $10 \mathrm{~s}(10,14,15)$. Adenosine is also metabolized by xanthine oxidase in the intracellular space of endothelial, smooth muscle, and red blood cells (9-11).

Usual Indications. The chronotropic, dromotropic, and inotropic actions associated with receptor $\mathrm{A}_{1}$ allow adenosine to be used for managing sinoatrial node activity, atrioventricular node conductivity, and ventricular automaticity (15). The main indication for adenosine is to restore sinus rhythm in paroxysmal supraventricular tachycardia $(9,15)$.

Use in Nuclear Medicine. Adenosine is used as a vasodilatory agent for the performance of cardiac stress testing for those unable to exercise adequately (e.g., vascular disease, 


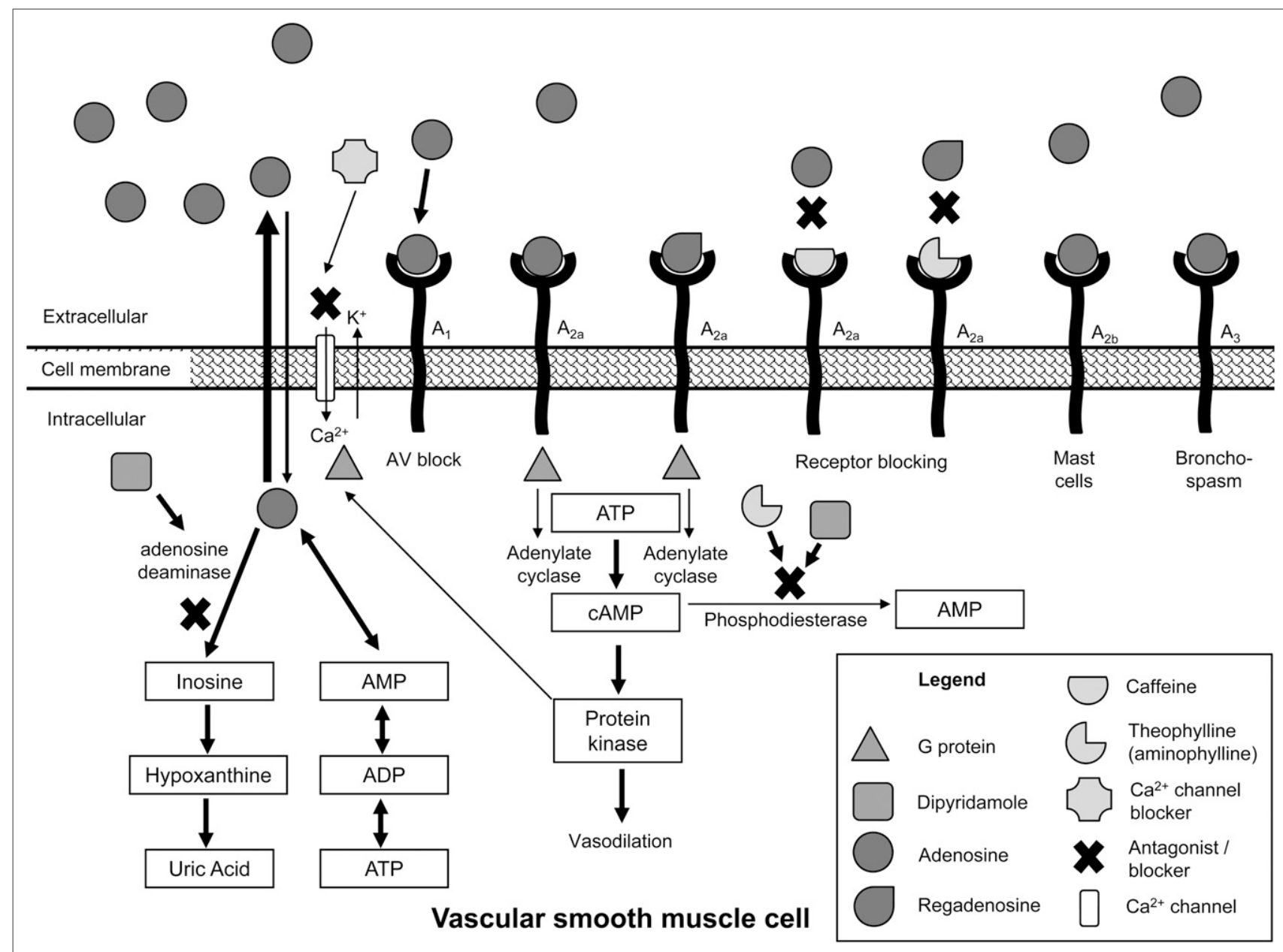

FIGURE 2. Schematic representation of action of vasodilating agents in vascular smooth muscle cell. Endogenous adenosine is produced in vascular smooth muscle cells and leaves cell. In extracellular space, endogenous and exogenous adenosine can couple with 4 types of adenosine receptors. Receptor $A_{1}$ couples with adenylate cyclase inhibitory $G$ protein to produce atrioventricular (AV) block and some bronchoconstriction. Receptor $\mathrm{A}_{3}$ couples with adenylate cyclase inhibitory $\mathrm{G}$ protein to produce bronchoconstriction. Receptor $A_{2 b}$ couples with adenylate cyclase, stimulating $G$ protein to produce mast cell degranulation, peripheral vasodilation, and antiplatelet activity. Receptor $A_{2 a}$ couples with adenylate cyclase, stimulating $G$ protein to convert adenosine triphosphate (ATP) to cyclic adenosine monophosphate (cAMP) and produce coronary and peripheral vasodilation. Regadenoson is selective for receptor $A_{2 a}$ to produce vasodilation. Caffeine has greater selectivity for receptors $A_{1}$ and $A_{2 a}$ to antagonize those actions. Theophylline (aminophylline and tea) has 3-5 times higher potency than caffeine in antagonizing receptors $A_{1}$ and $A_{2 a}$, whereas theobromine (typical of chocolate) has lower potency than caffeine. Dipyridamole antagonizes adenosine deaminase, which reduces adenosine metabolism and thus increases availability of adenosine in extracellular space. Dipyridamole is also phosphodiesterase inhibitor so blocks conversion of cyclic adenosine monophosphate to adenosine monophosphate, further increasing vasodilation. Calcium channel blockers act to antagonize voltage-dependent calcium channel to block vasodilation. ADP = adenosine diphosphate.

respiratory disease, musculoskeletal limitations, calcium channel blockers, $\beta$-blockers, or poor motivation) and in cardiac PET $(4,7,16)$. Adenosine increases coronary blood flow 4-5 times normal in normal blood vessels and to a lesser extent in stenosed vessels (16). This exaggeration in blood flow differences between normal and stenosed vessels is the basis for detecting hemodynamically significant disease.

Proper Use and Dose Administration. The dose is administered intravenously as $140 \mu \mathrm{g} / \mathrm{kg} / \mathrm{min}$ for $6 \mathrm{~min}$ with radiopharmaceutical injection at $3 \mathrm{~min}$ after commencement of infusion. Alternatively, incremental doses of 50, 75, 100, and $140 \mu \mathrm{g} / \mathrm{kg} / \mathrm{min}$ are given each minute then maintained at $140 \mu \mathrm{g} / \mathrm{kg} / \mathrm{min}$ until $7 \mathrm{~min}$ (Fig. 4) $(8,12,15,17$ ). The radiopharmaceutical is injected intravenously $3 \mathrm{~min}$ after commencement of the adenosine infusion. Although the 6-min method is recommended, a common alternative is $140 \mu \mathrm{g} /$ $\mathrm{kg} / \mathrm{min}$ intravenously for $4 \mathrm{~min}$ with radiopharmaceutical injection at 2 min after commencement of infusion.

Contraindications. Adenosine is contraindicated in patients with sick sinus syndrome, second- or third-degree atrioventricular block, asthma, or a history of bronchospasm $(8,12,14,15)$. Adenosine is relatively contraindicated in known hypersensitivity, unstable angina, oral dipyridamole use, and hypotension $(8,14)$.

Warnings and Precautions. Adenosine should be used with caution in patients on medications that suppress sinoatrial or 


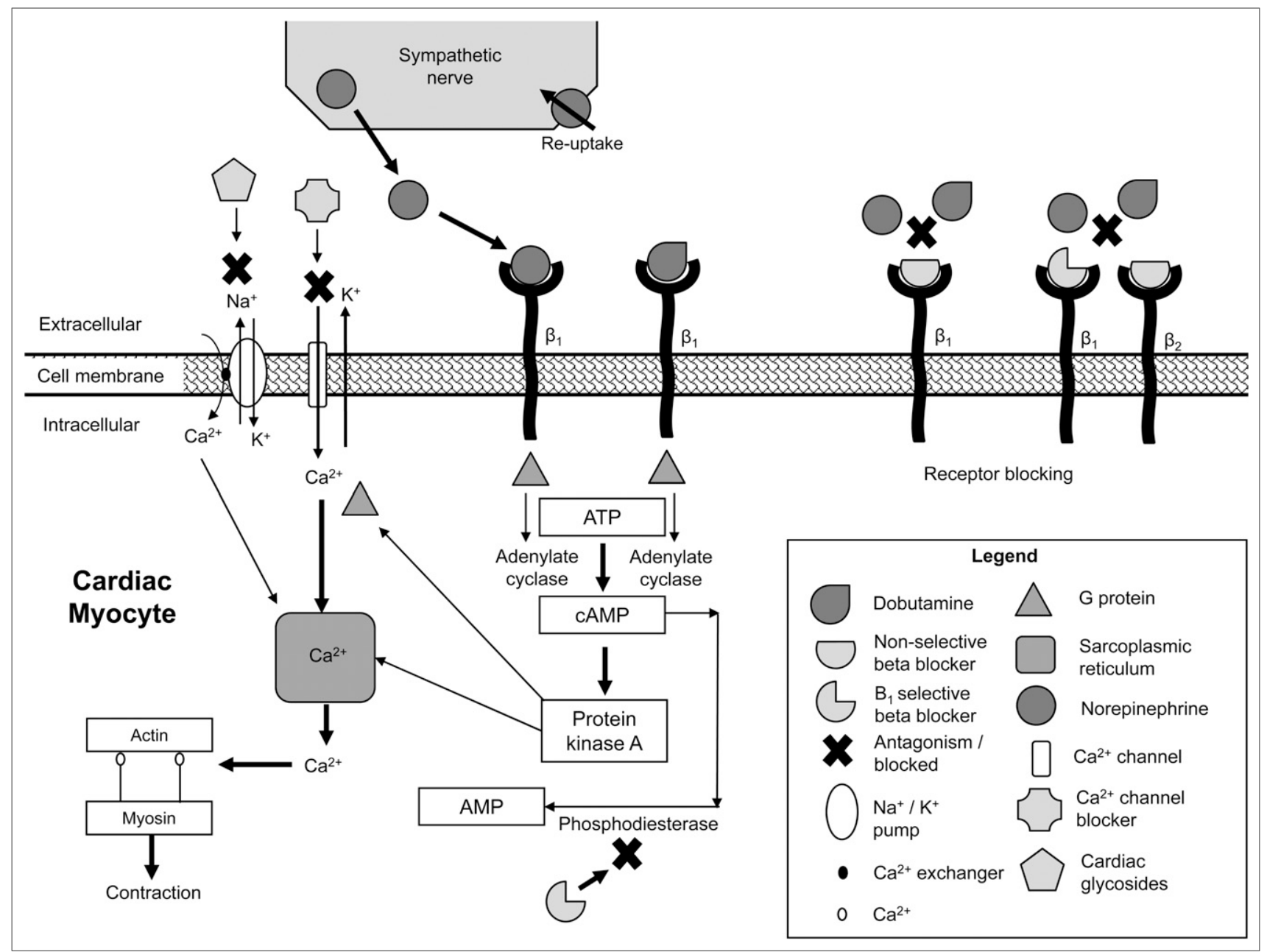

FIGURE 3. Schematic representation of action of inotropic/chronotropic agents in cardiac myocyte. Endogenous norepinephrine is released from sympathetic nerve. In reuptake mechanism failure (e.g., heart failure), excess norepinephrine is available for $\beta_{1}$ activation. In extracellular space, endogenous norepinephrine and exogenous dobutamine can couple with $\beta_{1}$-receptors. Receptor $\beta_{1}$ couples with adenylate cyclase, stimulating $G$ protein to drive increased intracellular calcium, which facilitates formation of actin-myosin cross bridges and produces increased force and rate of contraction. This response can be antagonized by $\beta$-blocker either nonselective (e.g., propranolol) or selective (e.g., atenolol) for $\beta_{1}$. Calcium channel blockers act to antagonize voltagedependent calcium channel to block inotropic and chronotropic contraction response. Likewise, cardiac glycosides such as digoxin antagonize sodium/potassium pump to increase intracellular calcium via calcium exchanger, increasing force of contraction. cAMP = cyclic adenosine monophosphate; ATP = adenosine triphosphate.

atrioventricular nodes (additive or synergistic effects may result) (14).

Adverse Reactions. Adenosine itself is not selective for particular receptor subtypes. Consequently, several unwanted effects accompany adenosine stress. These are generally resolved rapidly by cessation of the infusion, since adenosine has a duration of action of less than $1 \mathrm{~min}$ and a very short biologic half-life $(<10 \mathrm{~s})(7,9-11,15)$.

Commonly seen adverse reactions include chest pain, pain in the throat/jaw and arm, headache, flushing, and dyspnea (7,14-16). Electrocardiogram changes and atrioventricular block are also occasionally noted $(10,16)$. Some patients experience lightheadedness, gastrointestinal discomfort, paraesthesia, and hypotension (14). It is worth noting that $10.6 \%$ of patients experience these adverse effects several hours after cessation of the infusion, despite the very short half-life (14).
Despite being an antiarrhythmic medication, adenosine can potentiate arrhythmia (15). Bronchospasm, particularly in asthmatics, is a significant potential adverse reaction (15).

Common Interactions. Caffeine and similar xanthine products antagonize adenosine but in doing so can potentiate peripheral effects of adenosine (e.g., vasodilator-induced renin release) $(5,7,8)$. Adenosine effects are potentiated by dipyridamole $(10,15)$.

\section{Dipyridamole (Persantine; Boehringer Ingelheim)}

General Information/Drug Class. Dipyridamole is an indirect potent vasodilator pyridopyrimidine compound with adenosine reuptake inhibition and phosphodiesterase inhibition producing vasodilatory and antiplatelet activity $(10,15)$. 


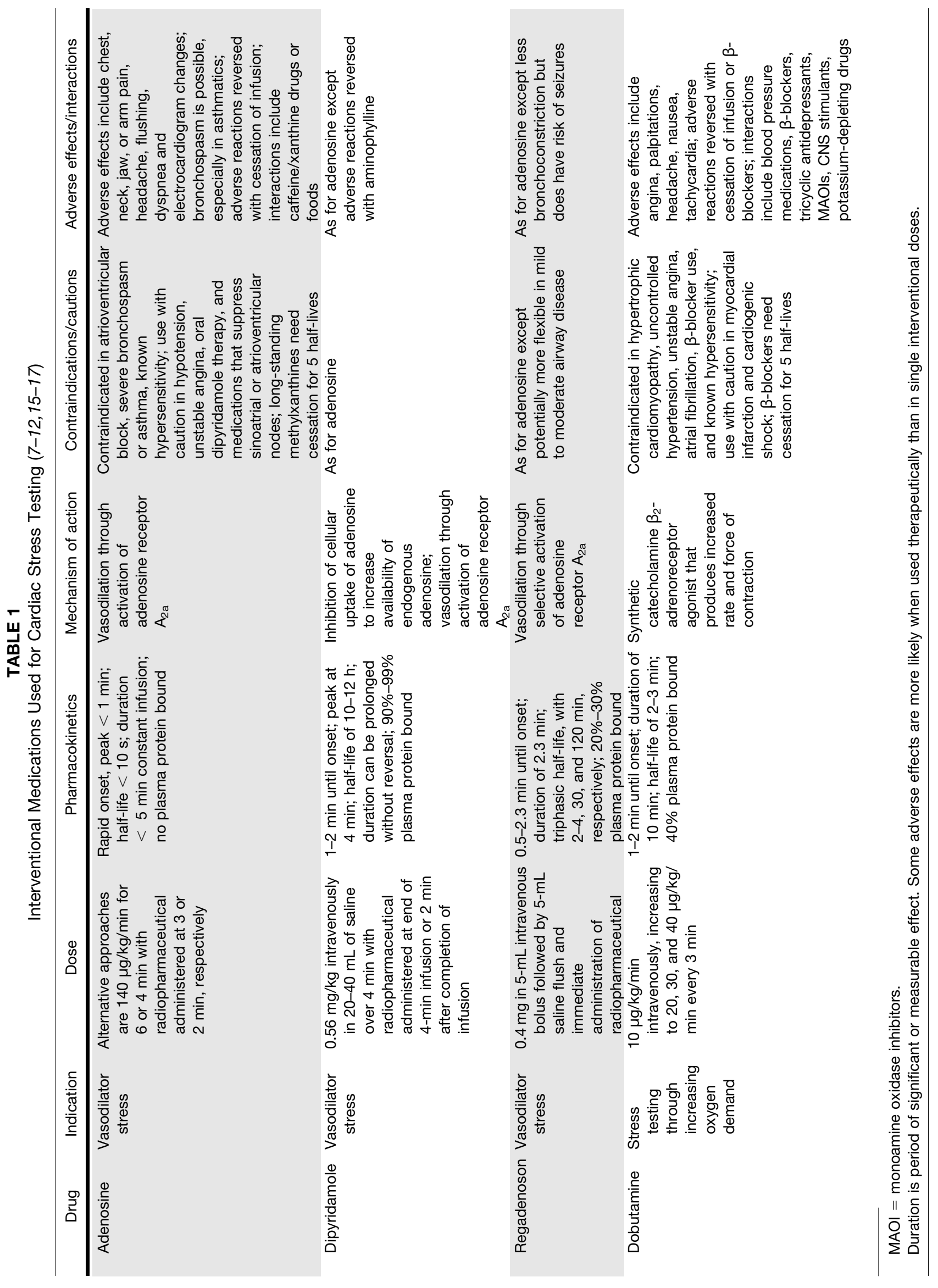




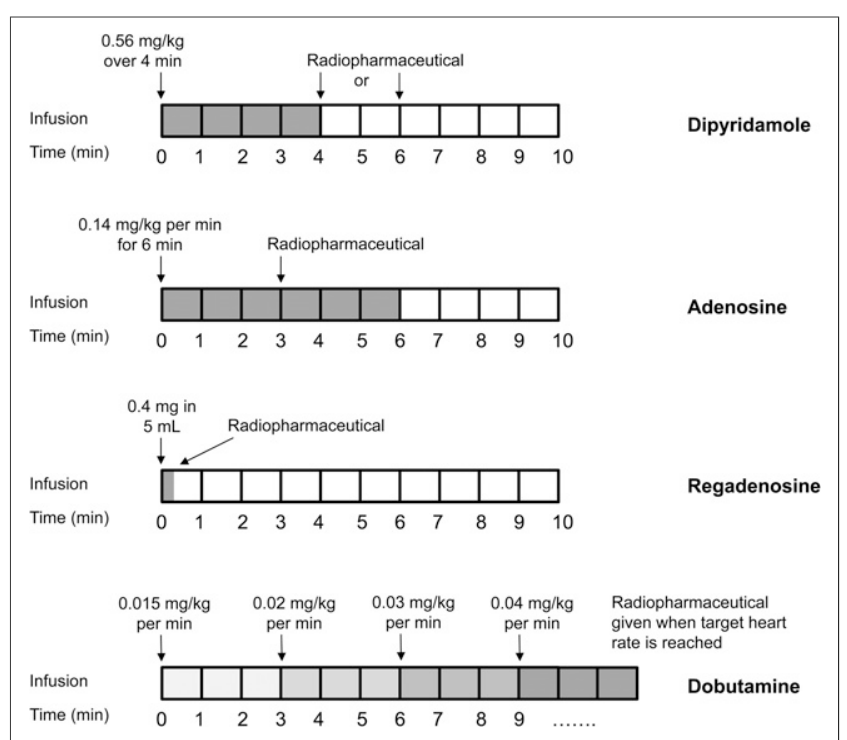

FIGURE 4. Comparison of infusion techniques for main pharmacologic stress agents.

Mode of Action. Dipyridamole is a pyridopyrimidine compound with both vasodilatory and antithrombotic effects $(10,17)$. Adenosine deaminase is an enzyme that catalyzes the deamination of adenosine to inosine (Fig. 2) $(14,18)$. Dipyridamole inhibits adenosine deaminase, which is an enzyme involved in cellular uptake of adenosine. By blocking cellular uptake in myocardial, endothelial, and blood cells, dipyridamole increases extracellular interstitial adenosine $(10,14)$. Consequently, the increased adenosine has increased reactivity with adenosine receptors that regulate coronary blood flow, which leads to vasodilation $(12,14,16,17)$. In blood cells, inhibition of phosphodiesterase increases cyclic adenosine monophosphate, which reduces activation of cell aggregation (10).

Pharmacokinetics. Dipyridamole is incompletely absorbed from the gut, has 90\%-99\% plasma protein binding, and has a 10- to 12-h half-life $(10,15)$. It is metabolized in the liver and mostly eliminated in bile, with a small fraction via urine (15).

Usual Indications. Dipyridamole is used as an antiplatelet medication for thromboembolism prophylaxis, especially after stroke or valve replacement (usually in oral dose form) $(10,15)$.

Use in Nuclear Medicine. Dipyridamole is used as an indirect vasodilatory agent for the performance of cardiac stress testing for those unable to exercise adequately (e.g., vascular disease, respiratory disease, musculoskeletal limitations, calcium channel blockers, $\beta$-blockers, or poor motivation) $(4,7,16)$.

Proper Use and Dose Administration. A dose of 0.56 $\mathrm{mg} / \mathrm{kg}$ of dipyridamole diluted in $20-40 \mathrm{~mL}$ of saline is infused over 4 min intravenously. The maximum vasodilatation occurs at 4 min after the end of the infusion, but the radiopharmaceutical is administered at either 0 or 2 min after infusion (Fig. 4) $(8,12,17)$.

Contraindications. Dipyridamole is contraindicated in patients with sick sinus syndrome, second- or third-degree atrioventricular block, asthma, or a history of bronchospasm $(12,14,15)$. Hypersensitivity to dipyridamole or aminophylline is also a relative contraindication (14).

Warnings and Precautions. Because adenosine shunts endocardial blood flow to the epicardium, there may be a reduction in collateral blood supply or induction of ischemia (12). Severe ischemic symptoms may occur. Orthostatic hypotension may also occur. Severe hepatic dysfunction needs to be managed with caution because of liver metabolism (16). Caution should also be exercised in known hypotension, aortic stenosis, heart failure, recent myocardial infarction, coagulation disorders, and angina $(15,16)$. Careful consideration should be exercised in patients not abstaining from xanthine medications and products because of the potential for false-negative results (14).

Adverse Reactions. For dipyridamole, $47 \%$ of patients report adverse reactions, of which $0.26 \%$ are severe (12). Significant adverse reactions can be treated with intravenous aminophylline or nitroglycerine for chest pain. Frequent adverse reactions include chest pain, headache, and dizziness. Less commonly, patients experience nausea, flushing, tachycardia, dyspnea, hypotension, and electrocardiogram changes (14-16). Patients with severe $\mathrm{CAD}$ or conduction abnormalities are at greater risk of adverse effects (14).

Common Interactions. Dipyridamole can potentiate the effects of anticoagulants and potentially inhibit fludarabine uptake, reducing efficacy (15). Interestingly, alcohol (ethanol) consumption has also been reported to increase adenosine levels by decreasing adenosine reuptake (19). Thus, alcohol consumption might potentiate the effects of dipyridamole and decrease antagonism by xanthines (reduce the half-life of caffeine).

\section{Regadenoson (Lexiscan; Astellas)}

General Information/Drug Class. Regadenoson is a potent adenosine derivative vasodilator with selectivity for receptor $\mathrm{A}_{2 \mathrm{a}}$.

Mode of Action. Regadenoson is an adenosine derivative that is a selective $\mathrm{A}_{2 \mathrm{a}}$ agonist and extends several potential advantages over adenosine (Fig. 2) $(8,20,21)$ : it is given as an intravenous bolus at a fixed dose, which simplifies the infusion process; it produces fewer undesirable side effects (e.g., atrioventricular block and bronchospasm) because of the $A_{2 a}$ selectivity; and it can be used in patients with mild to moderate reactive airway disease.

Most clinical evaluations tend to focus on its being "not inferior" to adenosine rather than on any specific tangible benefits over adenosine ( 8 ).

Pharmacokinetics. Regadenoson is given by intravenous bolus injection, with onset of action (increased coronary blood flow) occurring at $0.5-2.3 \mathrm{~min}$ after injection and $2.3 \mathrm{~min}$ being the recognized duration of action (22). Approximately 
$20 \%-30 \%$ of regadenoson is plasma protein-bound, and it is not rapidly metabolized like adenosine (22). Regadenoson undergoes triphasic elimination, with half-lives of 2$4 \mathrm{~min}, 30 \mathrm{~min}$, and $2 \mathrm{~h}(22)$.

Usual Indications. Regadenoson was developed specifically for stress testing.

Use in Nuclear Medicine. Regadenoson is a vasodilatory pharmacologic stress agent with specific application in patients with mild to moderate airway disease.

Proper Use and Dose Administration. The standard dose is $0.4 \mathrm{mg}$ in $5 \mathrm{~mL}$ by intravenous injection over $10 \mathrm{~s}$ followed by a $5-\mathrm{mL}$ bolus saline flush, after which the radiopharmaceutical dose is injected (Fig. 4).

Contraindications. Contraindications are as for adenosine, with some flexibility in mild to moderate airway disease.

Warnings and Precautions. Warnings and precautions are as for adenosine; however, regadenoson also decreases the seizure threshold so should be used with caution in those with a history of seizures.

Adverse Reactions. Regadenoson has a 13-fold lower affinity for $\mathrm{A}_{1}$ receptors than $\mathrm{A}_{2 \mathrm{~A}}$ but is 10 times more potent than adenosine (23). Despite the selective $A_{2 A}$ agonism designed to eliminate bronchoconstriction, there is a surprisingly high incidence of dyspnea reported (8). The most common adverse reactions include dyspnea, headache, nausea, abdominal discomfort, and ventricular conduction abnormalities, all occurring more frequently than with adenosine $(8)$. Less frequently occurring than adenosine are flushing, chest pain, angina, and atrioventricular block (8). The use of regadenoson has an increased risk of seizures not evident with adenosine (22).

Common Interactions. Common interactions are as for adenosine.

\section{Dobutamine (Dobutrex; Eli Lilly)}

General Information/Drug Class. Dobutamine is a sympathomimetic $\beta_{1}$-agonist with positive inotropic (increased contractility) and chronotropic (increased heart rate) effects $(9,10,14,15)$.

Mode of Action. Adrenergic $\beta$-receptors are important to understand in cardiac pharmacology and will be discussed further under $\beta$-blockers. There are 3 subtypes for $\beta$-adrenergic receptors designed to respond to catecholamines: $\beta_{1}$, $\beta_{2}$, and $\beta_{3}$. $\beta_{1}$-receptors are found in the heart and kidneys, with responsibility for increasing the rate and force of cardiac contraction and renin secretion, respectively. $\beta_{2}$-receptors are found in the lungs, liver, and skeletal muscle, causing, when activated by an agonist, vasodilation, bronchodilation, glycogenolysis, and glucagon release. $\beta_{3}$-receptors are found in adipose tissue, with responsibility for lipolysis.

Dobutamine is a powerful positive inotropic and chronotropic sympathomimetic drug with a primary mechanism of action through direct stimulation of $\beta_{1}$-receptors of the sympathetic nervous system $(9,10,16)$. Dobutamine also demonstrates weak $\beta_{2}$-agonist activity (vasodilation) and $\alpha_{1}$ activity (increases intracellular calcium concentrations) (10). In the extracellular space, endogenous norepinephrine and exogenous dobutamine can couple with $\beta_{1}$-receptors (Fig. 3). Receptor $\beta_{1}$ couples with an adenylate cyclasestimulating $G$ protein to drive increased intracellular calcium, which facilitates formation of actin-myosin cross bridges and produces an increased force and rate of contraction (9-11). Arbutamine has been used as an alternative to dobutamine, with similar inotropic and chronotropic actions but less peripheral vasodilation (4).

Pharmacokinetics. Dobutamine is inactive orally (15). The onset of action is $1-2 \mathrm{~min}$ after intravenous injection, and the duration of action is $10 \mathrm{~min}(10,11)$. The half-life after intravenous injection is just 2-3 min $(10,11,15)$. Dobutamine is rapidly metabolized in the liver and conjugates with glucuronic acid before being excreted mainly in urine, with a small fraction in feces $(11,15)$.

Usual Indications. Dobutamine is used to treat acute heart failure and septic shock by increasing cardiac output $(11,15)$.

Use in Nuclear Medicine. The primary advantage of dobutamine in nuclear cardiology is the minimal $\beta_{2}$ activity, which significantly reduces the risks in those with respiratory compromise $(7,14)$. The absence of bronchospasm makes dobutamine the pharmacologic stress agent of choice (over dipyridamole, adenosine, and regadenoson) for patients with asthma or obstructive airway disease $(7,14,16)$. From a practical sense, dobutamine can be used in patients who have consumed caffeine and is ideal in patients who are physically limited from undertaking exercise stress.

Proper Use and Dose Administration. The dose is administered as an incremental dose of $10-40 \mu \mathrm{g} / \mathrm{kg} / \mathrm{min}$ every $3 \mathrm{~min}$ (Fig. 4) (15,17). The radiopharmaceutical is administered when the target heart rate is reached.

Contraindications. The main contraindications are hypersensitivity to dobutamine, hypertrophic cardiomyopathy, noncessation of $\beta$-blockers, uncontrolled hypertension, unstable angina, atrial fibrillation, aortic stenosis, ventricular arrhythmias, and pheochromocytomas $(11,14,15)$.

Warnings and Precautions. Caution should be exercised when using dobutamine in patients with acute myocardial infarction and cardiogenic shock (15). It is possible that dobutamine can interfere with the uptake of the radiopharmaceutical in myocardial perfusion imaging, and vasodilators are therefore preferred (7).

Adverse Reactions. A wide range of adverse effects is possible with sympathomimetics, reflective of sympathetic nervous system stimulation $(11,15)$. Dose-related increases in heart rate, blood pressure, angina, and palpitation can occur $(11,15)$. There is a greater risk of arrhythmia and decreased blood pressure (12). Angina, palpitations, headache, nausea, and tachycardia are seen in $31 \%-70 \%$ of patients $(11,14-16)$. Although a short half-life allows adverse reaction resolution with infusion cessation, a fast-acting $\beta$-blocker (e.g., esmolol) may be used to reverse dobutamine $(14,16)$.

Common Interactions. Dobutamine will interact with $\beta$-blockers and with medications that affect blood pressure (15). Severe interactions to be avoided can occur with monoamine oxidase inhibitors, tricyclic antidepressants, 
TABLE 2

Adjunctive Medications Commonly Used in Nuclear Cardiology (7-12,15-17)

\begin{tabular}{|c|c|c|c|}
\hline Drug/indication/dose & $\begin{array}{c}\text { Pharmacokinetics/mechanism } \\
\text { of action }\end{array}$ & Contraindications/cautions & Adverse effects/interactions \\
\hline $\begin{array}{l}\text { Aminophylline/reverse } \\
\text { dipyridamole/125-250 } \\
\text { mg by slow intravenous } \\
\text { infusion }\end{array}$ & $\begin{array}{l}\text { Rapid onset and peak; half-life } \\
\text { of } 8 \mathrm{~h} ; 50 \%-70 \% \text { plasma } \\
\text { protein bound; antagonizes } \\
\text { all adenosine receptors }\end{array}$ & $\begin{array}{l}\text { No absolute contraindication; } \\
\text { however, caution in } \\
\text { patients with porphyria, } \\
\text { hyperthyroidism, hypertension, } \\
\text { arrhythmia, heart failure, and } \\
\text { liver dysfunction }\end{array}$ & $\begin{array}{l}\text { Adverse effects include CNS } \\
\text { stimulation, gut disturbances, } \\
\text { headache, and palpitations; } \\
\text { interactions include xanthine } \\
\text { products and medications, } \\
\text { medications altering liver } \\
\text { metabolism, acyclovir, } \\
\text { allopurinol, some } \\
\text { antiarrhythmics, } \\
\text { antidepressants, cimetidine, } \\
\text { disulfiram, fluvoxamine, } \\
\text { interferon-a, macrolide } \\
\text { antibacterials and quinolones, } \\
\text { oral contraceptives, } \\
\text { tiabendazole, viloxazine, } \\
\text { phenytoin and antiepileptics, } \\
\text { phenobarbitone, ritonavir, } \\
\text { rifampicin, sulfinpyrazone, } \\
\text { lithium, macrolides, } \\
\text { pancuronium, and phenytoin }\end{array}$ \\
\hline $\begin{array}{l}\text { Nitroglycerin/relieve acute } \\
\text { angina/300- to } 600-\mu g \\
\text { sublingual tablet or } 1-2 \\
\text { sprays of } 400 \mu g \text { each } \\
\text { onto or under tongue or } \\
2-\text { to } 3-m g \text { buccal tablet }\end{array}$ & $\begin{array}{l}\text { 1-3 min until onset; half-life of } \\
2-3 \text { min; duration of } 30- \\
60 \text { min; facilitates nitric } \\
\text { oxide metabolism, which } \\
\text { causes vasodilation and } \\
\text { reduced preload and } \\
\text { afterload }\end{array}$ & $\begin{array}{l}\text { Contraindicated in hypotension, } \\
\text { hypovolemia, and increased } \\
\text { intracranial pressure; } \\
\text { contraindicated with phenytoin, } \\
\text { alteplase, levofloxacin, and } \\
\text { sildenafil; caution in renal } \\
\text { and liver dysfunction and } \\
\text { hypothyroidism }\end{array}$ & $\begin{array}{l}\text { Adverse effects include flushing, } \\
\text { dizziness, tachycardia and } \\
\text { headache; interactions include } \\
\text { alcohol, antihypertensives, and } \\
\text { vasodilators }\end{array}$ \\
\hline $\begin{array}{l}\text { Salbutamol/relieve } \\
\text { dyspnea and } \\
\text { bronchospasm/1-2 } \\
\text { inhalations of } 100 \mu \mathrm{g} \\
\text { each, with third } \\
\text { inhalation if necessary } \\
1 \text { min after second }\end{array}$ & $\begin{array}{l}5 \text { min until onset; peak at } \\
60 \text { min; half-life of } 4-6 \mathrm{~h} \text {; } \\
\text { duration of } 3-6 \mathrm{~h} \text {; direct- } \\
\text { acting } \beta_{2} \text {-agonist to dilate } \\
\text { bronchi }\end{array}$ & $\begin{array}{l}\text { Contraindicated in hypotension; } \\
\text { caution in hyperthyroidism, } \\
\text { myocardial insufficiency, } \\
\text { hypertension, arrhythmia, and } \\
\text { diabetes mellitus }\end{array}$ & $\begin{array}{l}\text { Adverse reactions include tremor, } \\
\text { palpitations, tachycardia, } \\
\text { anxiety, headaches, peripheral } \\
\text { vasodilation, muscle cramps, } \\
\text { hyperglycemia, and } \\
\text { hypersensitivity; interactions } \\
\text { with other } \beta_{2} \text {-agonists, } \\
\text { corticosteroids, diuretics, } \\
\text { xanthines, } \beta \text {-blockers, and } \\
\text { antidepressants }\end{array}$ \\
\hline
\end{tabular}

Some adverse effects are more likely when used therapeutically than in single adjunctive doses.

CNS stimulants, and drugs that deplete potassium (e.g., diuretics, corticosteroids, and aminophylline) (15).

\section{ADJUNCTIVE MEDICATIONS}

Adjunctive medications are those that may be used to directly respond to the patient's status during a nuclear medicine procedure. Given that the emergency cart will be discussed in a separate article, this section will limit discussion to the reversal of pharmacologic interventions and the use of salbutamol and nitroglycerin to manage acute adverse reactions. These adjunctive medications are summarized in Table 2.

\section{Aminophylline}

General Information/Drug Class. Aminophylline is a methylxanthine that is described as a xanthine-based antiasthma class medication $(11,15)$. Aminophylline itself is a prodrug that, after administration, rapidly releases theophylline as its active bronchodilating constituent (15). Aminophylline is also a phosphodiesterase inhibitor, antagonizes CNS adenosine receptors causing stimulation, and has diuretic action stronger than caffeine (15).

Mode of Action. Although theophylline antagonizes all adenosine receptors, it has a greater effect on $\mathrm{A}_{2}$ receptors (9-11). Antagonism of $A_{1}$ receptors reduces bronchoconstriction, increases CNS activity, and increases cardiac contraction force, whereas $\mathrm{A}_{2 \mathrm{~A}}$ receptor antagonism blocks vasodilation, blocks antiplatelet activity, and increases CNS activity (Fig. 2) (10,11). Theophylline also inhibits phosphodiesterase, causing an increase in cyclic adenosine monophosphate, which in turn leads to smooth muscle relaxation and stimulation of cardiac muscles (9-11). Inhibition of 
phosphodiesterase, in theory at least, results in bronchodilation and an increased cardiac contraction rate and force, but this generally requires therapeutic doses $(9,10)$.

Aminophylline is the prodrug ester derivative of theophylline. Aminophylline (or theophylline in vivo) has higher affinity for adenosine receptors than does adenosine itself and, thus, provides effective blockade $(9,11)$. Aminophylline does not reduce the amount of either dipyridamole or adenosine but simply displaces them because of preferential binding.

Pharmacokinetics. Theophylline gut absorption is unpredictable and can cause gastric irritation $(10,11)$. Consequently, theophylline is given as the more soluble aminophylline, which is rapidly hydrolyzed into theophylline and ethylenediamine at a ratio of 2:1 and a half-life of several minutes $(10,15)$. Theophylline is $50 \%-70 \%$ plasma protein-bound. It is metabolized in the liver with urinary excretion, and $10 \%$ is excreted in urine unchanged $(11,15)$.

Theophylline and caffeine are metabolized in liver by CYP450, with elimination half-lives of 8 and 4-6h, respectively $(9,15)$. The half-lives do, however, vary significantly among individuals. In particular, nicotine smoking decreases half-life by $50 \%$, oral contraceptive use doubles half-life, the last trimester of pregnancy substantially increases half-life $(15 \mathrm{~h})$, liver disease increases half-life, alcohol consumption decreases half-life, and age increases half-life $(9,15)$.

Usual Indications. As an antiasthmatic medication, aminophylline is not the first-line therapy but rather is reserved for unresponsive life-threatening acute asthma (15). It can be used as a general bronchodilator in asthma and chronic obstructive airway disease management (15).

Use in Nuclear Medicine. Theophylline competitively antagonizes adenosine at all adenosine receptor subtypes to reverse the effects of dipyridamole infusion. There is no need to reverse adenosine infusion, because there is a short half-life of less than $10 \mathrm{~s}$; however, the prolonged activity of dipyridamole in increasing the availability of extracellular adenosine requires antagonism.

Proper Use and Dose Administration. The standard reversal dose is $50-250 \mathrm{mg}$ of aminophylline by slow intravenous infusion to avoid adverse CNS and cardiovascular stimulant effects (15). There are several approaches. One is to include reversal only when patient symptoms warrant; another is aminophylline reversal in all patients immediately after the stress test. An alternative approach adopted at some sites is to use aminophylline reversal only for severe symptoms or for mild symptoms not resolved by a strong cup of coffee.

Warnings and Precautions. There are no specific contraindications, but caution should be exercised in patients who are already taking xanthine medications or have peptic ulcer disease (oral dose), porphyria, hyperthyroidism, hypertension, cardiac arrhythmia, heart failure, liver dysfunction, or epilepsy $(11,15)$.

Adverse Reactions. Hypersensitivity to the ethylenediamine component of aminophylline is possible (15). Tolerance can occur (15). Dose-dependent adverse effects include CNS stimulation, gut disturbances (even intravenous), nausea, vomiting, diarrhea, abdominal pain, headache, insomnia, anxiety, irritability, tremor, and palpitations $(11,15)$. Overdosage can cause excessive diuresis, dehydration, tachycardia, hypotension, and metabolic acidosis $(11,15)$. Overdosage can be treated with activated charcoal to increase elimination or decrease absorption of oral doses or $\beta$-blockers (15).

Common Interactions. Theophylline can interact with other medications that can enhance or reduce liver metabolism (15). Xanthine effects are additive with aminophylline $(9,15)$. The effects of aminophylline can be potentiated by $\beta_{1}$-agonists and diuretics (11). Clearance of aminophylline can be reduced by acyclovir, allopurinol, some antiarrhythmics, antidepressants, cimetidine, disulfiram, fluvoxamine, interferon $\alpha$, macrolide antibacterials and quinolones, oral contraceptives, tiabendazole, and viloxazine $(11,15)$. Clearance can be increased by phenytoin and antiepileptics, phenobarbitone, ritonavir, rifampicin, and sulfinpyrazone $(11,15)$. Theophylline can reduce the concentrations of lithium, macrolides, pancuronium, and phenytoin (11).

\section{Nitroglycerin (Glyceryl Trinitrate)}

General Information/Drug Class. Nitroglycerin is a nitrovasodilator/organic nitrate.

Mode of Action. Essentially, nitroglycerin enhances oxygen delivery and reduces oxygen demand (9-11). Nitrites and nitrogen compounds enter the endothelial cell and are converted from arginine to nitric oxide (and citrulline), which in turn stimulates guanylate cyclase metabolism in smooth muscle cells (Fig. 5) (9-11,15). The resultant cyclic guanosine monophosphate activates a protein kinase causing protein phosphorylation $(9-11,15)$. Vasodilation is associated with the reduction in calcium concentration and dephosphorylation of myosin $(9-11,15)$. Nitroglycerin results in pooling of blood in veins and, by reducing the amount of blood returned to the heart, decreases preload (left ventricular end-diastolic volume) and decreases myocardial oxygen demand $(10,11,15)$.

At low doses, nitroglycerin produces venodilation and reduced preload $(9,11,15)$. Higher doses produce arterial dilation, which reduces afterload (resistance against contraction). Reducing both preload and afterload effectively reduces the primary determinants of myocardial oxygen demand (15). Nitroglycerin also causes dilation of coronary (and collateral) vessels to more efficiently distribute blood and oxygen to ischemic tissues $(9-11,15)$.

Two important relationships need to be outlined for nitroglycerin. First, nitric oxide reacts with metals, thiols, and oxygen and as such can modify proteins, lipids, and DNA (9). Second, phosphodiesterase-5 inhibitors used for erectile dysfunction, such as sildenafil (Viagra; Pfizer), function by potentiating the effects of nitric oxide in the corpora cavernosa $(9,10)$.

Pharmacokinetics. Nitroglycerin is rapidly absorbed from oral mucosa, but bioavailability is reduced by extensive first-pass 


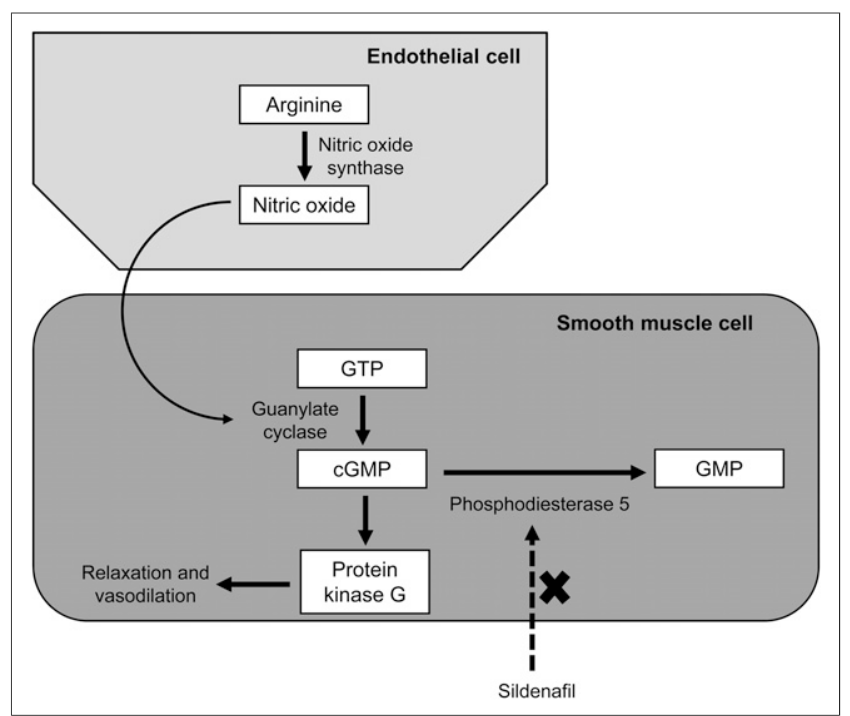

FIGURE 5. Schematic representation of production of nitric oxide in endothelial cells with subsequent activation of guanylate cyclase in smooth muscle cells. This facilitates conversion of guanine triphosphate (GTP) to cyclic guanosine monophosphate (cGMP), activating protein kinase $G$, which leads to smooth muscle relaxation and vasodilation. Cyclic guanosine monophosphate is converted to guanosine monophosphate by phosphodiesterase 5. Thus, use of phosphodiesterase inhibitors such as sildenafil blocks this conversion, potentiating effects of cyclic guanosine monophosphate. It is essential, therefore, to be aware of potential sildenafil use in patients who may receive cardiac medications and, in particular, nitroglycerin.

metabolism in the liver $(9-11,15)$. Other routes of administration see rapid activation by liver metabolism (9). Effects are therapeutic immediately after intravenous administration, 1-3 min after sublingual or buccal administration, and 3060 min after transdermal or ointment application $(9-11,15)$. Duration of effect varies from 3-5 min for intravenous, 30$60 \mathrm{~min}$ for sublingual, and $3-5 \mathrm{~h}$ for buccal, to $24 \mathrm{~h}$ for transdermal $(9-11,15)$. Nitroglycerin is metabolized in the liver and eliminated via the kidneys, with a plasma half-life of 2-3 min (9-11).

Usual Indications. Nitroglycerin is the initial therapy for treating ischemia and angina pectoris $(9-11,15)$. It has also been used for treatment of heart failure and myocardial infarction $(9-11,15)$.

Use in Nuclear Medicine. Nitroglycerin is used to treat acute angina in response to stress testing and is generally administered in the form of sublingual spray/tablet or buccal tablets for rapid onset and relief of symptoms (15).

Proper Use and Dose Administration. For application in nuclear medicine in response to acute angina $(11,15)$, the dose can be a 300 - to $600-\mu \mathrm{g}$ sublingual tablet, 1 or 2 sprays of $400 \mu \mathrm{g}$ each directed onto or under the tongue, ora 2- to 3mg buccal tablet placed between the upper lip and gum. Sublingual tablet or spray doses can be repeated if necessary at 5-min intervals, but failure to respond to a maximum of 3 repeated doses requires medical intervention. The mouth should not be rinsed for $5 \mathrm{~min}$ after administration.
Contraindications. Nitroglycerin is contraindicated with phenytoin, alteplase, and levofloxacin (15). Concurrent use with phosphodiesterase type 5 inhibitors such as sildenafil is also contraindicated $(9,11,15)$. Nitrates are contraindicated in cardiomyopathy, hypotension, hypovolemia, aortic or mitral stenosis, severe anemia, and increased intracranial pressure $(11,15)$.

Warnings and Precautions. Caution should be exercised in renal and liver dysfunction and in hypothyroidism (15). Sublingual and buccal preparations can reduce effectiveness associated with changes to oral moisture (15). Tolerance can develop $(10,11)$.

Adverse Reactions. Flushing, dizziness, tachycardia, and headache are common $(10,11,15)$. Larger doses can lead to vomiting, restlessness, vision disturbances, hypotension, and syncope $(10,15)$. On rare occasions, nitroglycerin may lead to cyanosis, respiratory dysfunction, and bradycardia (15).

Common Interactions. Alcohol, antihypertensives, and other vasodilators enhance hypotension (11).

\section{Salbutamol/Albuterol}

General Information/Drug Class. Salbutamol is a directacting sympathomimetic $\beta_{2}$-agonist.

Mode of Action. $\beta_{2}$-agonists such as salbutamol dilate the bronchi by direct action (Fig. 6). Salbutamol mimics the effects of endogenous norepinephrine by coupling with $\beta_{2^{-}}$ receptors on the surface of bronchial smooth muscle cells. Receptor $\beta_{2}$ couples with a $G$ protein, stimulating adenylate cyclase to decrease intracellular calcium $(9,11)$. This leads to calcium efflux from the cell and uptake in the sarcoplasmic reticulum, stripping calcium from actin-myosin bridges to produce smooth muscle relaxation and bronchodilation $(9,11)$. Short-acting salbutamol is given by inhalation for direct action and symptom relief (9). Salmeterol is a longeracting $\beta_{2}$-agonist used regularly as a symptom preventer (9).

Pharmacokinetics. After inhalation, 10\%-20\% of the dose reaches the lower airways for direct action on smooth muscle (15). The direct action and rapid onset combined with the half-life make salbutamol a short-acting bronchodilator suitable as a symptom reliever (11). It is not metabolized in the lung but does undergo first-pass metabolism in the liver $(11,15)$. Of the remainder not inhaled, that component swallowed will be readily absorbed from the gut (15). Salbutamol and its metabolites are rapidly excreted in urine, with a small amount of fecal elimination. Plasma half-life is $4-6 \mathrm{~h}(15)$.

There is a rapid onset of action after inhalation $(<5 \mathrm{~min})$, with peak effect at $1 \mathrm{~h}$ and duration of action lasting 3-6 h $(9,11,15)$. If given orally, the onset of action is $30 \mathrm{~min}$, with a peak at 2-3 h and duration of $6 \mathrm{~h}(15)$.

Usual Indications. High intravenous doses have been used to delay labor (15). Salbutamol is a bronchodilator for reversible airway obstruction (e.g., asthma and chronic obstructive airway disease) $(9,15)$.

Use in Nuclear Medicine. Nuclear medicine patients having reversible respiratory difficulties, including during or after stress testing (including exercise) may have symptom relief with salbutamol. 


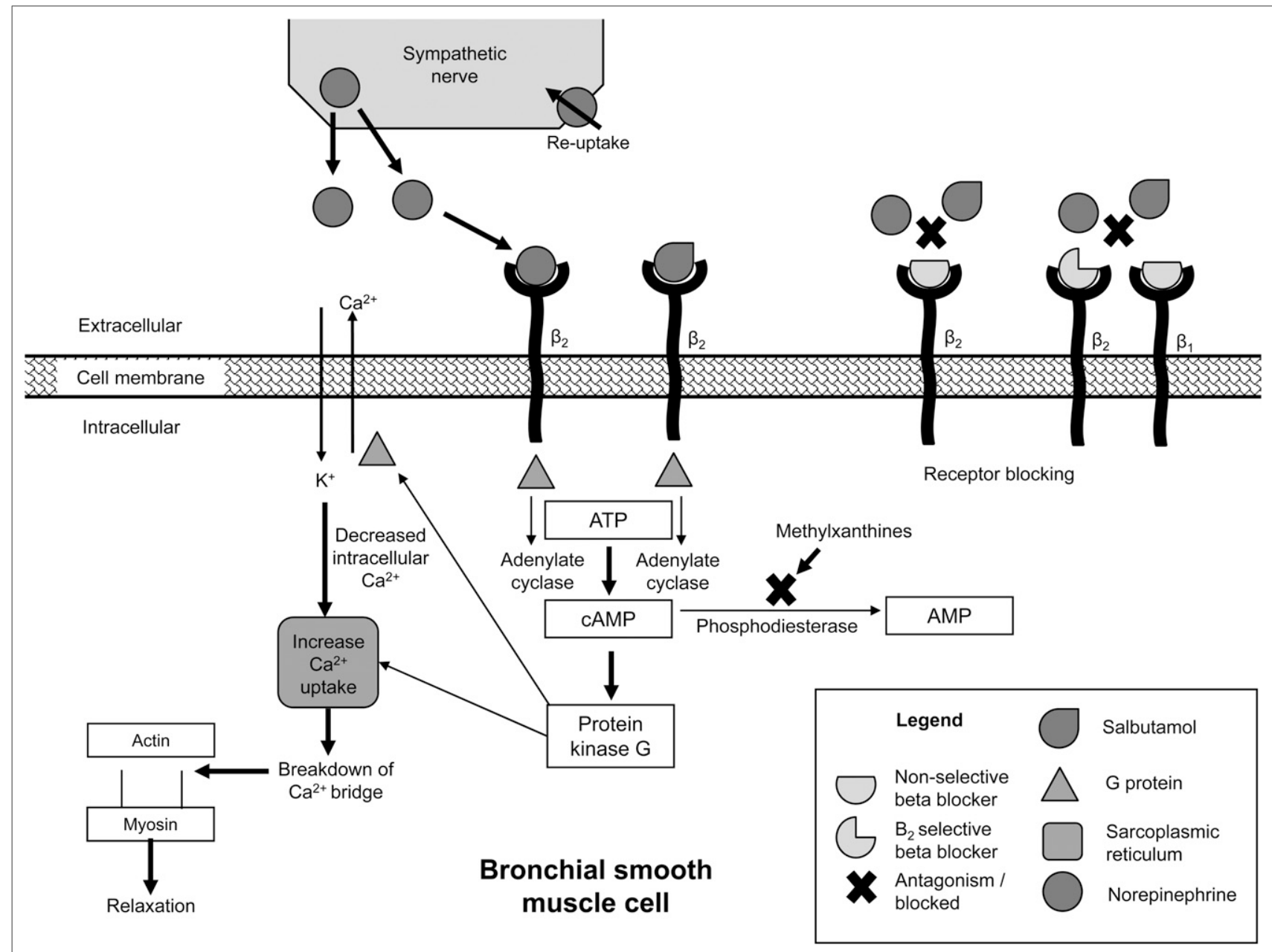

FIGURE 6. Schematic representation of action of $\beta$-agonism in bronchial smooth muscle. Endogenous norepinephrine is released from sympathetic nerve. In extracellular space, endogenous norepinephrine and exogenous salbutamol can couple with $\beta_{2}$-receptors. Receptor $\beta_{2}$ couples with adenylate cyclase, stimulating $G$ protein to produce decreased intracellular calcium through calcium efflux and uptake in sarcoplasmic reticulum, leading to reduction in actin-myosin bridge formation, producing smooth muscle relaxation and bronchodilation. Inhibition of phosphodiesterase conversion of cyclic adenosine monophosphate (cAMP) to adenosine monophosphate by methylxanthines (e.g., caffeine, theobromine, and theophylline) further decreases intracellular calcium. This response can be antagonized by $\beta$-blocker either nonselective (e.g., labetalol) or selective (e.g., butoxamine) for $\beta_{2}$. ATP = adenosine triphosphate.

Proper Use and Dose Administration. For relief of acute bronchospasm, 1-2 inhalations of $100 \mu \mathrm{g}$ each are given, with a third inhalation if necessary 1 min after the second $(11,15)$. This same dose can be given prophylactically before stress testing (15).

Contraindications. Hypotension is a contraindication.

Warnings and Precautions. Hyperthyroidism, myocardial insufficiency, hypertension, arrhythmia, and diabetes mellitus are the main precautions $(11,15)$. Plasma potassium levels should be monitored in severe asthma to minimize synergistic effects of medications causing hypokalemia (15).

Adverse Reactions. Adverse effects are reduced through inhalation and selectivity for $\beta_{2}$ (15). Tremor, palpitations, tachycardia, anxiety, headaches, peripheral vasodilation, muscle cramps, and hyperglycemia are the main adverse reactions $(11,15)$. Hypersensitivity has occurred and may manifest as paradoxic bronchospasm, angioedema, urticaria, or hypotension (15).
Common Interactions. An increased risk of hypokalemia is associated with concurrent use with other $\beta_{2}$-agonists, corticosteroids, diuretics, and xanthines $(11,15)$. Concurrent use with other sympathomimetics may cause sympathetic excitation, whereas $\beta$-blockers antagonize effects (11). Antidepressant medications may potentiate cardiovascular effects (e.g., tachycardia) (11).

\section{CESSATION MEDICATIONS}

There are several medications a patient may be taking that can interfere with nuclear cardiology studies, directly or through interference with the stress component of the study. A blanket cessation rule may be in place to uncomplicate patient preparation, but 3 considerations need to be mentioned. First, the nuclear medicine study may be attempting to assess patient status on the medication. Second, withholding the medication may compromise the patient, including 
the ability to undergo the nuclear medicine study. Third, not all cessation medications apply to each stress-testing approach. How long medications are withheld should be determined by their half-life; typically, 5 half-lives is adequate. Prescribed medications should be ceased only on consultation with the patient's physician. Medications that are generally ceased for a nuclear cardiology study are discussed below and summarized in Table 3.

\section{Xanthines}

Xanthines are purines found throughout the body and structurally resemble adenine and guanine. The basic xanthine structure is, therefore, similar to the adenine portion of adenosine, and this similarity allows antagonism of adenosine (11). Methylation $\left(\mathrm{CH}_{3}\right)$ of the xanthine produces several methylxanthines, including caffeine, theobromine, and theophylline. Caffeine is typically found in coffee, tea, guarana, and yerba mate; theobromine in chocolate and yerba mate; and theophylline mostly in tea (and aminophylline).

Although theophylline antagonizes all adenosine receptors (Fig. 2), it has a greater effect on $\mathrm{A}_{2}$ receptors. Caffeine tends to be more selective for $A_{1}$ and $A_{2 A}$, and theobromine has higher activity for $A_{1}(19)$. Generally speaking, a single cup of strong coffee provides sufficient caffeine to block less than $20 \%$ of $\mathrm{A}_{1}$ and $\mathrm{A}_{2 \mathrm{~A}}$ receptors $(5,19)$. To achieve $50 \%$ antagonism would require 5 times higher plasma concentrations, and $80 \%$ antagonism would need 25 times high plasma concentrations $(5,19)$.

Methylxanthines also inhibit phosphodiesterase, causing an increase in cyclic adenosine monophosphate, which in turn leads to smooth muscle relaxation (Fig. 6) and stimulation of cardiac muscles (Fig. 3) (9-11). Although this potentially results in bronchodilation and increased cardiac contraction rate and force, therapeutic-range doses might be required $(9,10)$.

Structurally, xanthine is a weak antagonist, and the simple addition of a methyl $\left(\mathrm{CH}_{3}\right)$ group in theobromine increases receptor affinity by a factor of 40 (24). A further methyl group (theophylline and caffeine) provides affinity 80 times that of xanthine (24). Adenosine has significantly lower affinity than theophylline, allowing theophylline to displace adenosine at receptors. The $\mathrm{NH}_{3}$ or $\mathrm{CH}_{3}$ groups on various xanthines also change their potency. Although caffeine has high affinity it has poor potency; theobromine has low affinity and low potency, and theophylline has high affinity and high potency. This consideration does question whether chocolate (theobromine) should be ceased before a myocardial perfusion stress test.

Caffeine. Caffeine is almost completely absorbed (99\%) in the gastrointestinal tract within 45 min of consumption; however, plasma concentrations resulting from the same caffeine ingestion can vary from one person to the next by as much as 16-fold (19). Caffeine is metabolized in liver by CYP450 with an elimination half-life of 4-6 h, but this can increase with oral contraceptive use, pregnancy, and liver disease or can decrease with nicotine and alcohol use $(9,19)$. The major metabolites of caffeine include paraxanthine, which approximates caffeine in potency; theobromine (low potency); and theophylline (3-5 times more potent) (19).

Managing methylxanthine cessation, therefore, requires an understanding of the affinity, potency, and sources of caffeine (5,19): $150 \mathrm{~mL}$ of coffee contains 40-180 $\mathrm{mg}$ of

TABLE 3

Cessation Medications Commonly Used in Nuclear Cardiology That, in Consultation with Primary Care Physician, Should Be Stopped for 5 Half-Lives of the Medication

\begin{tabular}{|c|c|c|}
\hline Drug & Cessation window & Comments \\
\hline Nitrates & $\begin{array}{l}\text { 12-24 } \mathrm{h} \text { for exercise, vasodilator, and } \\
\text { dobutamine stress testing }\end{array}$ & $\begin{array}{l}24 \mathrm{~h} \text { of cessation should be used for long-acting nitrates; } 1 \mathrm{~h} \\
\text { of cessation can be used for short-acting nitrates delivered } \\
\text { in sublingual forms. For patches, cessation commences at } \\
\text { time patch is removed }\end{array}$ \\
\hline$\beta$-blockers & $\begin{array}{l}48 \mathrm{~h} \text { for exercise and dobutamine } \\
\text { stress testing }\end{array}$ & $\begin{array}{l}24 \mathrm{~h} \text { is sufficient for those with shorter half-lives, but longer } \\
\text { than } 48 \mathrm{~h} \text { may be required for longer half-lives; refer to } \\
\text { specific half-life of } \beta \text {-blocker in use for potential variations }\end{array}$ \\
\hline Calcium channel antagonists & $\begin{array}{l}48 \mathrm{~h} \text { for exercise, vasodilator, and } \\
\text { dobutamine stress testing }\end{array}$ & $\begin{array}{l}24 \mathrm{~h} \text { is sufficient for those with shorter half-lives, but longer } \\
\text { than } 48 \mathrm{~h} \text { may be required for longer half-lives; refer to } \\
\text { specific half-life of calcium channel blocker in use for } \\
\text { potential variations }\end{array}$ \\
\hline $\begin{array}{l}\text { Methylxanthine foods and } \\
\text { caffeinated drinks }\end{array}$ & $12-24 \mathrm{~h}$ for vasodilator stress testing & $\begin{array}{l}\text { There is unlikely to be marginal benefit beyond a } 24-\mathrm{h} \\
\text { cessation; however, } 6 \mathrm{~h} \text { may be sufficient for those with } \\
\text { mild consumption; caffeine and theophylline products } \\
\text { (coffee, tea) are of importance, but theobromine } \\
\text { (chocolate) is less likely to have benefits from cessation }\end{array}$ \\
\hline Methylxanthine medications & $\begin{array}{l}\text { 1-5 d for vasodilator stress testing, } \\
\text { depending on formulation }\end{array}$ & $\begin{array}{l}\text { Refer to specific half-life of medication to determine } \\
\text { appropriate cessation period; most medications are } \\
\text { theophylline-based or caffeine-containing; thus, } 24 \mathrm{~h} \text { is } \\
\text { adequate for most (unless in controlled-release form) }\end{array}$ \\
\hline Dipyridamole & $12-24 \mathrm{~h}$ for vasodilator stress testing & $\begin{array}{l}\text { Half clearance time for dipyridamole should allow cessation } \\
\text { period of } 12 \mathrm{~h} \text { to be used if urgent }\end{array}$ \\
\hline Digoxin & $\begin{array}{l}2 \text { wk for exercise and dobutamine } \\
\text { stress testing }\end{array}$ & $\begin{array}{l}\text { Longer time should be considered in known renal } \\
\text { dysfunction }\end{array}$ \\
\hline
\end{tabular}


caffeine; $150 \mathrm{~mL}$ of decaffeinated coffee, $2-8 \mathrm{mg} ; 150 \mathrm{~mL}$ of tea, including iced tea, $24-50 \mathrm{mg} ; 150 \mathrm{~mL}$ of cocoa, $2-7$ $\mathrm{mg} ; 28 \mathrm{~g}$ of milk chocolate, $1-15 \mathrm{mg} ; 28 \mathrm{~g}$ of dark chocolate, 5-36 g; $180 \mathrm{~mL}$ of soft drink, 15-24 mg; and $180 \mathrm{~mL}$ of energy drinks such as Red Bull, $80 \mathrm{mg}$.

Caffeine (100 mg or more) is also contained in some medications, including, but not limited to, migraine medications, pain relievers, diuretics, cold remedies, menstrual products, weight control medications, and stimulants.

A single cup of coffee produces serum caffeine levels of $0.004 \mathrm{mM}$, blocking $18 \%$ of adenosine receptors, and toxicity occurs at $0.25 \mathrm{mM}$ (90\% blockade) (19). In the unlikely scenario of caffeine toxicity in a stress-test patient, 6 half-lives $(30 \mathrm{~h})$ would return serum caffeine levels to the equivalent of 1 cup of coffee. Also unlikely is $50 \%$ receptor blockade $(0.02 \mathrm{mM})$, but this would require only 2 halflives $(10 \mathrm{~h})$ to return to the equivalent of a single cup. Thus, the first $12 \mathrm{~h}$ of caffeine abstinence provides a tangible benefit to patient preparation (dipyridamole and adenosine stress patients), whereas the marginal benefit beyond $24 \mathrm{~h}$ is very small. A more intuitive approach might lead to greater compliance with both patient preparation and scanning.

\section{$\beta$-Blockers}

As previously outlined, there are 3 subtypes for $\beta$-adrenergic receptors, with the two of interest being $\beta_{1}$-receptors (found in the heart and kidneys, with responsibility for increasing the rate and force of cardiac contraction and renin secretion, respectively) and $\beta_{2}$-receptors (found in the lungs, liver, and skeletal muscle, causing vasodilation, bronchodilation, glycogenolysis, and glucagon release) (9-11).

Antagonists of the $\beta$-adrenergic receptors are referred to as $\beta$-blockers and function by competitive blockade of the actions of catecholamines (Figs. 3 and 5) $(9-11,17)$. $\beta$-blockers can be selective for either $\beta_{1}$ (atenolol, bisoprolol, esmolol, and metoprolol) or $\beta_{2}$ (butoxamine); however, it is common for $\beta$-blockers to be nonselective (propranolol, sotalol, oxprenolol, and pindolol) or nonselective for $\alpha$ - and $\beta$-receptors (labetalol and carvedilol), although they do not generally act on $\beta_{3}(9)$. A clinically important role of $\beta$-blockers is to limit the response to exercise or other excitatory stimuli $(9-11,17)$. Thus, at exercise or excitation, $\beta_{1}$-blockers (or cardioselective blockers) work to reduce heart rate, cardiac output, and arterial pressure $(9-11,17)$. At high doses, selective $\beta_{1}$-blockers can also inhibit the action of $\beta_{2}$-receptors (11). This is particularly important in nuclear cardiology because $\beta$-blockers limit maximal response to exercise, and thus, pharmacologic vasodilation stress is required for patients on a $\beta$-blocker whose medication cannot be withheld for the purpose of stress testing. Furthermore, $\beta$-blockers in those with asthma can inhibit bronchodilation (9-11). Dobutamine stress, as a $\beta$-agonist, is unsuitable in patients on $\beta$-blockers for obvious reasons. Furthermore, $\beta$-blockers limit vasodilation of skeletal muscles and can potentially reduce exercise capacity $(9,10)$. As a selective $\beta_{2}$-blocker, butoxamine would not require cessation before an exercise or dobutamine stress test.
Using the 5-half-life rule of thumb for cessation of medications before exercise or dobutamine stress testing, the following cessation times apply (11): atenolol for 30$35 \mathrm{~h}$ (half-life, 6-7 h; 50\% bioavailability, $85 \%-100 \%$ renal elimination); bisoprolol for 50-60 h (half-life, 10$12 \mathrm{~h} ; 80 \%$ bioavailability, $50 \%$ renal elimination $/ 50 \%$ hepatic elimination); metoprolol for 15-25 h (half-life, 3-5 h; $40 \%$ bioavailability, $90 \%$ hepatic elimination); propranolol for 15-30 h (half-life, 3-6 h; 25\% bioavailability, 99\% hepatic elimination); sotalol for 35-90 h (half-life, $7-18 \mathrm{~h} ; 100 \%$ bioavailability, $90 \%$ renal elimination); oxprenolol for 5-15 h (half-life, $1-3 \mathrm{~h} ; 24 \%-60 \%$ bioavailability, 95\% hepatic elimination); pindolol for 15$20 \mathrm{~h}$ (half-life, 3-4 h; 75\% bioavailability, 50\% renal elimination $/ 50 \%$ hepatic elimination); labetalol for $30-40 \mathrm{~h}$ (half-life, 6-8 h; 20\% bioavailability, 95\% hepatic elimination); and carvedilol for 30-50 h (half-life, 6-10 h; 25\% bioavailability, $75 \%$ hepatic elimination).

\section{Calcium Channel Blockers}

Calcium channel blockers stop the influx of calcium through the calcium channel of cell membranes in both cardiac myocytes and smooth muscle cells (9-11). Calcium channel blockers decrease the intracellular calcium concentration, reducing the release of calcium from the sarcoplasmic reticulum and thus blunting the calcium-driven excitationcontraction coupling of actin-myosin cross bridges (9-11). Consequently, calcium channel blockers reduce cardiac contraction force (negative inotrope), which makes them incompatible with effective exercise or pharmacologic stress testing (Figs. 2 and 3). Calcium channel blockers can be used to treat angina, tachyarrhythmias, and hypertension (9-11).

Calcium channel blockers are metabolized in the liver (CYP3A4) to metabolites that tend to have their own activity (9-11). Given the CYP3A4 metabolism, a wide variety of drug interactions can occur, and these will vary from one medication to another. However, calcium channel blockers generally interact with $\beta$-blockers, carbamazepine, cyclosporin, digoxin, and inhibitors of CYP3A4 (e.g., grapefruit juice).

Using the 5-half-life rule of thumb for cessation of medications before exercise or pharmacologic stress testing, the following cessation times apply (11): amlodipine for 175-225 h (half-life, 35-45 h; 65\% bioavailability); diltiazem for $20 \mathrm{~h}$ (half-life, $4 \mathrm{~h} ; 40 \%-50 \%$ bioavailability); felodipine for 75-100 h (half-life, 15-20 h; 15\%-20\% bioavailability); nifedipine for $10 \mathrm{~h}$ (half-life, $2 \mathrm{~h} ; 50 \%$ bioavailability); and verapamil for $20 \mathrm{~h}$ (half-life, $4 \mathrm{~h} ; 20 \%$ bioavailability).

\section{Nitrates}

Organic nitrates, such as glyceryl trinitrate, have been discussed in detail above and outlined in Figure 6. As a cessation medication, the aforementioned vasodilatory effects in reducing both cardiac preload and afterload have the potential to interfere with the effectiveness of exercise and with vasodilatory and dobutamine stress testing. Unlike adenosine and dipyridamole, nitrates—importantly-dilate collateral blood supply (9). 
When considering the period of cessation before a myocardial perfusion stress test, consideration to both the medication half-life and the dose form needs to be given. The relatively rapid action of sublingual and buccal dose forms can reduce the cessation period compared controlledrelease dose forms (tablet or patches). More important is the elimination half-life. Short-duration nitrates such as glyceryl trinitrate with a plasma half-life of 2-3 min taken in the hours immediately preceding the stress test are unlikely to be prohibitive of performing the stress test, especially if delivered via sublingual or buccal routes. Conversely, longer-acting nitrates such as isosorbide mononitrate, with its 5-h plasma half-life regardless of the route of administration, will require cessation for $24 \mathrm{~h}$. Cessation commencement is when the last dose was administered or when the patch was removed.

\section{Digoxin}

Digoxin is a cardiac glycoside that originates from the foxglove plant (digitalis). Digoxin is used to treat heart failure and cardiac arrythmias (9-11). The action of digoxin is associated with the inhibition of the sodium/potassium pump (Fig. 3). Inhibition of the sodium/potassium pump increases intracellular sodium, which inhibits the efflux of calcium, increasing uptake of calcium in the sarcoplasmic reticulum (9-11). In turn, this provides more calcium ions for release to form actin-myosin bridges, which produce the excitation/contraction coupling and an increased cardiac contraction force (inotrope) (9-11). The increased contraction force and cardiac output are achieved without increased oxygen demand $(9,11,25)$. Digoxin produces a paradoxic negative chronotropic action (decreased rate of contraction) and slows atrioventricular conduction velocity (negative dromotropic) $(9,11,25)$. This effect is achieved by increasing resting membrane potentials, leading to decreasing the sensitivity of the sinoatrial and atrioventricular nodes to sympathetic and catecholamine stimuli $(9,11)$. The plasma half-life of digoxin is 20-50 h, which increases to 3-5 d in renal dysfunction $(9,11)$. Digoxin is primarily eliminated unchanged by the kidneys (80\%), with the remainder being eliminated by the biliary system without liver metabolism (11). Clearly, these actions interfere with exercise or dobutamine stress testing and require cessation for $2 \mathrm{wk}$-longer in patients with renal dysfunction.

Digoxin has a narrow therapeutic index and extensive list of drug interactions, perhaps the most important of which are those that increase digoxin serum levels (increased absorption or delayed elimination) and risk toxicity (e.g., amiodarone, calcium channel blockers, quinine, and spironolactone) (11). Digoxin is also associated with significant adverse effects, including nausea, vomiting, diarrhea, anorexia, visual disturbances, confusion, agitation, sleep disturbances, and, less commonly, arrythmias (11). Caution should be exercised when used with patients having renal or thyroid dysfunction, electrolyte imbalances, and acute myocardial infarction (11). Digoxin is contraindicated in patients with heart block, ventricular arrythmia, obstructive cardiomyopathy, cor pulmonale, constrictive pericarditis, and known hypersensitivity to digoxin (11).

\section{CONCLUSION}

Nuclear cardiology demands an understanding of basic pharmacology for interventional, adjunctive, and cessation medications. An insight into the complex interaction between interventional, adjunctive, and cessation medications in nuclear cardiology enhances practice and patient safety and ensures that nuclear medicine technologists meets the minimum capabilities for their scope of practice (1).

\section{DISCLOSURE}

No potential conflict of interest relevant to this article was reported.

\section{REFERENCES}

1. SNMMI-TS Scope of Practice Task Force. Nuclear medicine technologist scope of practice and performance standards. J Nucl Med Technol. 2017;45:325-336.

2. Currie GM. Pharmacology, part 1: introduction to pharmacology and pharmacodynamics. J Nucl Med Technol. 2018;46:81-86.

3. Currie GM. Pharmacology, part 2: introduction to pharmacokinetics. J Nucl Med Technol. 2018;46:221-230.

4. Travain MI, Wexler JP. Pharmacological stress testing. Semin Nucl Med. 1999;29: 298-318.

5. Currie GM, Wheat J, Wang L, Kiat H. Pharmacology in nuclear cardiology. Nucl Med Commun. 2011;32:617-627.

6. Leppo JA. Dipyridamole myocardial perfusion imaging. J Nucl Med. 1994;35: 730-733.

7. Saremi F, Jadvar H, Siegel ME. Pharmacologic interventions in nuclear radiology: indications, imaging protocols, and clinical results. Radiographics. 2002;22:477-490.

8. Druz RS. Current advances in vasodilator pharmacological stress perfusion imaging. Semin Nucl Med. 2009;39:204-209.

9. Rang H, Dale M, Ritter J, Flower R. Rang and Dale's Pharmacology. 6th ed. London, U.K.: Churchill Livingston; 2008.

10. Waller D, Renwick A, Hillier K. Medical Pharmacology and Therapeutics. 2nd ed. London, U.K.: Elsevier; 2006.

11. Bryant B, Knights K, Salerno E. Pharmacology for Health Professionals. 2nd ed. Sydney, Australia: Mosby Elsevier; 2007.

12. Theobald T. Sampson's Textbook of Radiopharmacy. 4th ed. London, U.K.: Pharmaceutical Press; 2011.

13. Zaret BL, Beller GA. Clinical Nuclear Cardiology: State of the Art and Future Directions. 3rd ed. Philadelphia, PA: Elsevier Mosby; 2005.

14. Loveless VS. Drugs Used as Interventional Agents in Nuclear Medicine. Albuquerque, NM: University of New Mexico Health Services Center; 1998.

15. Sweetman SC, ed. Martindale: The Complete Drug Reference. 26th ed. Chicago, IL: Pharmaceutical Press; 2009.

16. Park HM, Duncan K. Nonradioactive pharmaceuticals in nuclear medicine. J Nucl Med Technol. 1994;22:240-249.

17. Frishman WH, Sonnenblick EH. Cardiovascular Pharmacotherapeutics. New York, NY: McGraw Hill; 1996.

18. Patrick GL. An Introduction to Medicinal Chemistry. 3rd ed. New York, NY: Oxford University Press; 2005.

19. Fredholm BB, Battig K, Holmen J, Nehlig A, Zvartau E. Actions of caffeine in the brain with special reference to factors that contribute to its widespread Use. Pharmacol Rev. 1999;51:83-133.

20. Al Jaroudi W, Iskandrian AE. Regadenoson: a new myocardial stress agent. J Am Coll Cardiol. 2009;54:1123-1130.

21. Buhr C, Gössl M, Erbel R, Eggebrecht H. Regadenoson in the detection of coronary artery disease. Vasc Health Risk Manag. 2008;4:337-340.

22. Bengalorkar GM, Bhuvana K, Sarala N, Kumar TN. Regadenoson. J Postgrad Med. 2012;58:140-146.

23. Gao Z, Li Z, Baker SP. Novel short-acting $A_{2 A}$ adenosine receptor agonists for coronary vasodilation: inverse relationship between affinity and duration of action of $\mathrm{A}_{2 \mathrm{~A}}$ agonists. J Pharmacol Exp Ther. 2001;298:209-218.

24. Bruns RF, Daly JW, Snyder SH. Adenosine receptor binding: structure activity analysis generates extremely potent xanthine antagonists. Proc Natl Acad Sci USA. 1983;80:2077-2080.

25. Currie GM, Kiat H, Wheat J. Pharmacokinetic considerations for digoxin in older people. Open Cardiovasc Med J. 2011;5:130-135. 